\title{
Chloride channel diseases resulting from impaired transepithelial transport or vesicular function
}

\author{
Thomas J. Jentsch, Tanja Maritzen, and Anselm A. Zdebik \\ Zentrum für Molekulare Neurobiologie Hamburg, Universität Hamburg, Hamburg, Germany.
}

\begin{abstract}
The transport of anions across cellular membranes is crucial for various functions, including the control of electrical excitability of muscle and nerve, transport of salt and water across epithelia, and the regulation of cell volume or the acidification and ionic homeostasis of intracellular organelles. Given this broad range of functions, it is perhaps not surprising that mutations in $\mathrm{Cl}^{-}$channels lead to a large spectrum of diseases. These diverse pathologies include the muscle disorder myotonia, cystic fibrosis, renal salt loss in Bartter syndrome, kidney stones, deafness, and the bone disease osteopetrosis. This review will focus on diseases related to transepithelial transport and on disorders involving vesicular $\mathrm{Cl}^{-}$channels.
\end{abstract}

\section{Defects in transepithelial $\mathrm{Cl}^{-}$transport}

As $\mathrm{Cl}^{-}$channels allow only for the passive, diffusional flux of $\mathrm{Cl}^{-}$down its electrochemical gradient, the difference between cytoplasmic and extracellular $\mathrm{Cl}^{-}$concentration $\left(\left[\mathrm{Cl}^{-}\right]\right)$, together with the membrane voltage, determines whether the opening of $\mathrm{Cl}^{-}$channel will lead to an influx or efflux of this ion. Whereas in adult neurons intracellular $\left[\mathrm{Cl}^{-}\right]\left(\left[\mathrm{Cl}^{-}\right]_{\mathrm{i}}\right)$ is mostly below its equilibrium (predominantly because of the activity of the neuronal potassium chloride cotransporter $\mathrm{KCC} 2$; ref. 1), $\left[\mathrm{Cl}^{-}\right]_{\mathrm{i}}$ in epithelial cells is often in the $30-40 \mathrm{mM}$ range and thus above equilibrium at a voltage $(-50 \mathrm{mV})$ typical for these cells. Several cotransporters may contribute to the relatively high cytoplasmic $\left[\mathrm{Cl}^{-}\right]_{\mathrm{i}}$ in epithelia, most prominently NaK2Cl cotransporters. Opening of epithelial $\mathrm{Cl}^{-}$channels will therefore lead mostly to an efflux of $\mathrm{Cl}^{-}$, and the localization of these channels will determine the transport direction (Figure 1). Hence, apical $\mathrm{Cl}^{-}$channels are involved in $\mathrm{Cl}^{-}$secretion (as shown in Figure 1B), whereas basolateral $\mathrm{Cl}^{-}$channels play a role in $\mathrm{Cl}^{-}$(and salt) (re)absorption (Figure 1D).

\section{CFTR and cystic fibrosis}

Cystic fibrosis is the most common and best-known genetic disease involving a defect in transepithelial $\mathrm{Cl}^{-}$transport. It affects several epithelial organs, i.e., the lungs, pancreas, and intestine, among others. The most serious cystic fibrosis symptoms are generally observed in the lungs, where the fluid covering the airway epithelia becomes viscous and susceptible to bacterial infection.

CFTR, the cystic fibrosis transmembrane conductance regulator (2), functions as a cAMP- and ATP-regulated $\mathrm{Cl}^{-}$channel. This discovery came as a surprise, because CFTR belongs to the gene family of ABC transporters, which normally function as transport ATPases, but not as ion channels. However, the line separating ion channels from transporters may be thin, as recently demonstrated (3) by the $2 \mathrm{Cl}^{-} / \mathrm{H}^{+}$exchange activity of a bacterial homolog of mammalian $\mathrm{Cl}^{-}$ channels of the CLC gene family. In addition to the well-established function of CFTR as a $\mathrm{Cl}^{-}$channel, many regulatory roles have been ascribed to it, but some of these remain controversial (4-6). CFTR

Nonstandard abbreviations used: CFTR, cystic fibrosis transmembrane conductance regulator; $\left[\mathrm{Cl}^{-}\right], \mathrm{Cl}^{-}$concentration; $\left[\mathrm{Cl}^{-}\right]_{i}$, intracellular $\left[\mathrm{Cl}^{-}\right]$; DRA, downregulated in adenoma; $1,25(\mathrm{OH})_{2}-\mathrm{VitD}_{3}, 1,25$-dihydroxyvitamin $\mathrm{D}_{3}$; $\mathrm{PT}$, proximal tubule.

Conflict of interest: The authors have declared that no conflict of interest exists.

Citation for this article: J. Clin. Invest. 115:2039-2046 (2005).

doi:10.1172/JCI25470. may negatively regulate the epithelial $\mathrm{Na}^{+}$channel $\mathrm{ENaC}$, the activation of which may contribute to the cystic fibrosis lung phenotype $(4,7)$. However, the purported interaction of both channels was questioned by others (8). Recent data indicate that CFTR may directly activate the anion exchangers Slc26a3 (DRA, downregulated in adenoma) and Slc26a6 (PAT-1) (9). Certain CFTR mutations identified in patients may impair the $\mathrm{Cl}^{-} / \mathrm{HCO}_{3}{ }^{-}$exchange activity of these transporters (9) and thus could result in decreased pancreatic $\mathrm{HCO}_{3}{ }^{-}$secretion as is often observed in cystic fibrosis.

The role of CFTR in lung physiology is complex, and the cystic fibrosis lung pathology is not reproduced in mouse models. By contrast, the role of CFTR in colonic $\mathrm{Cl}^{-}$secretion is well understood (Figure 1B). In the colon, CFTR expression seems to be limited to crypts (10), which are the site of $\mathrm{Cl}^{-}$secretion (11). Like in other epithelia and consistent with a secretory role, CFTR is present in the apical membrane of the crypt cells. The opening of $\mathrm{CFTR} \mathrm{Cl}^{-}$channels, which is triggered by a rise in cAMP, leads to a passive efflux of $\mathrm{Cl}^{-}$because $\left[\mathrm{Cl}^{-}\right]_{\mathrm{i}}$ is elevated above equilibrium by the activity of basolateral NKCC1 $\mathrm{NaK} 2 \mathrm{Cl}$ cotransporters. $\mathrm{K}^{+}$ions that are taken up together with $\mathrm{Cl}^{-}$in a stoichiometrically coupled process need to be recycled through basolateral $\mathrm{K}^{+}$channels that are most likely heteromers of KCNQ1 and KCNE3 subunits (12), which are coexpressed in crypt cells $(12,13)$. As predicted by this model (Figure 1B), the disruption of CFTR in cystic fibrosis impairs colonic $\mathrm{Cl}^{-}$and fluid secretion. This results in thick feces (meconium ileus) in a subset of infants suffering from cystic fibrosis. Similar intestinal problems are the major phenotype observed in CFTR mouse models (14). Conversely, inadequately strong activation of CFTR by the drastic increase in cAMP that is elicited by cholera toxin leads to severe diarrhea, which can be alleviated in animal models by blocking of the basolateral $\mathrm{K}^{+}$conductance $(12,15)$.

\section{CFTR and ClC-2: a lack of synergism}

The cystic fibrosis phenotype may be modulated by the genetic background both in humans $(16,17)$ and in mice $(18,19)$. This has fueled speculations that other $\mathrm{Cl}^{-}$channels that are coexpressed in the same apical membranes as CFTR may partially compensate for its loss. In addition to putative $\mathrm{Ca}^{2+}$-activated $\mathrm{Cl}^{-}$channels $(18,20)$, the ubiquitously expressed $\mathrm{ClC}-2 \mathrm{Cl}^{-}$channel has been widely speculated to play such a role (21-23). However, mice in which both CFTR and ClC-2 were disrupted survived slightly better than CFTR $\mathrm{KO}$ mice and displayed neither lung nor pancreatic pathology (24). 


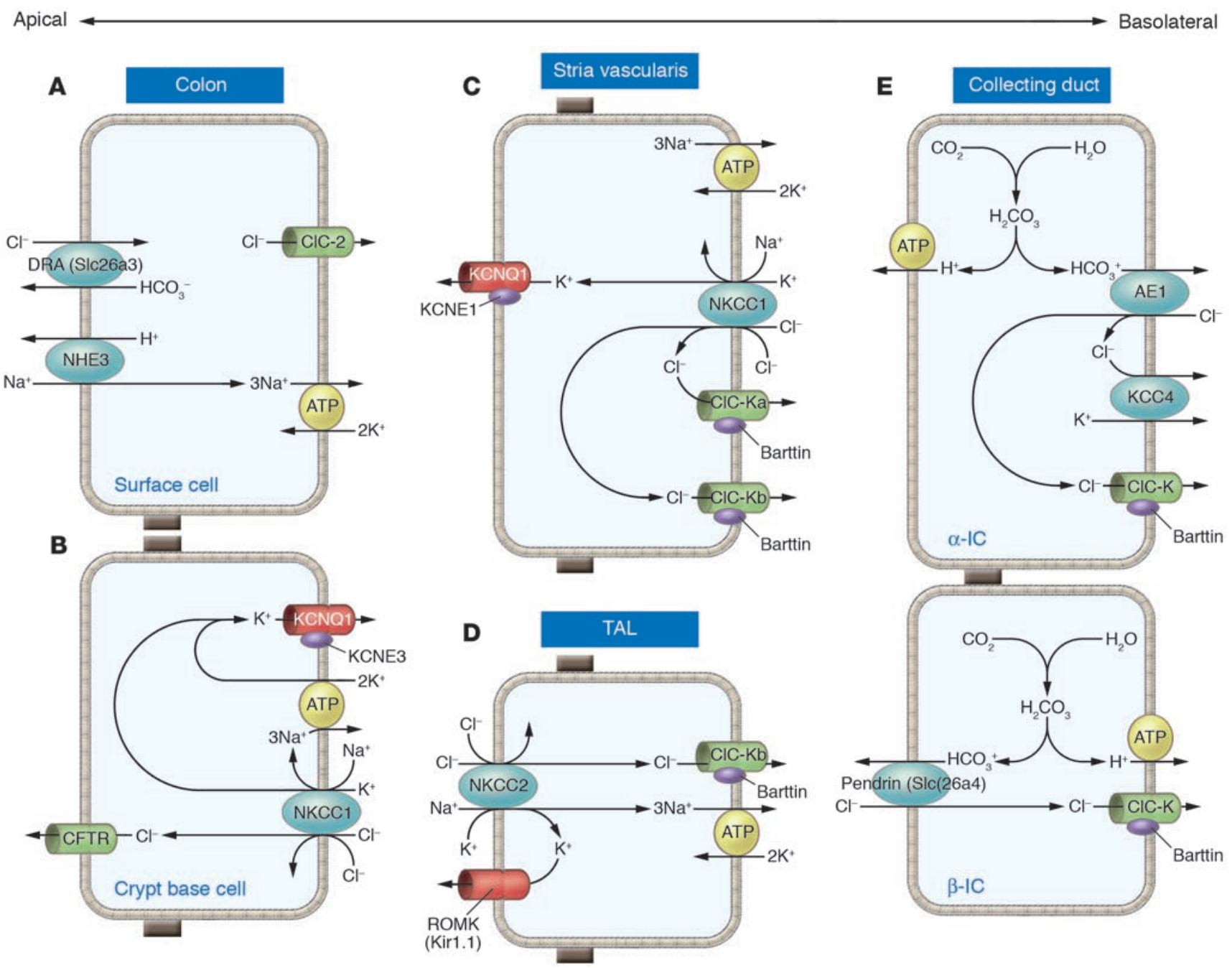

\section{Figure 1}

Diverse roles of $\mathrm{Cl}^{-}$channels in transepithelial transport. In colonic epithelia, cells at the luminal surface $(\mathbf{A})$ express a $\mathrm{Cl}^{-} / \mathrm{HCO}_{3}{ }^{-}$exchanger (which may be electrogenic) and the $\mathrm{Na}^{+} / \mathrm{H}^{+}$exchanger $\mathrm{NHE} 3$ in their apical membrane, allowing for net $\mathrm{NaCl}$ reabsorption. Chloride probably crosses the basolateral membrane through CIC-2. Cells at the crypt base (B) secrete chloride, which is taken up by basolateral NKCC1, through apical CFTR channels. KCNQ1/KCNE3 heteromeric $\mathrm{K}^{+}$channels are needed for $\mathrm{K}^{+}$recycling. (C) Model for $\mathrm{K}^{+}$secretion in the stria vascularis of the cochlea. $\mathrm{K}^{+}$is taken up by the basolateral isoform of the NKCC cotransporter, NKCC1, and the Na,K-ATPase. Chloride is recycled by basolateral $\mathrm{ClC}-\mathrm{Ka}$ and $\mathrm{ClC}-\mathrm{Kb} /$ barttin channels. (D) Model for $\mathrm{NaCl}$ reabsorption in the thick ascending limb of $\mathrm{Henle}$ (TAL). NaCl is taken up by the apical NKCC2 transporter that needs the apical ROMK channel for $\mathrm{K}^{+}$recycling. $\mathrm{Cl}^{-}$leaves the cell through basolateral $\mathrm{ClC}-\mathrm{Kb} / \mathrm{barttin}$ channels. (E) Model for intercalated cells of the collecting duct. $\alpha$-Intercalated cells $(\alpha-I C)$ secrete protons using a proton ATPase, while basolateral transport of acid equivalents is via the anion exchanger AE1. It is proposed that both KCC4 cotransporters (65) and CIC-K/barttin channels recycle $\mathrm{Cl}^{-}$. It is unknown whether $\mathrm{ClC}-\mathrm{K} /$ barttin is involved in $\mathrm{Cl}^{-}$reabsorption in $\beta$-intercalated cells as shown below.

Instead, they showed a superimposition of the intestinal phenotype of CFTR KO mice (14) with the retinal and testicular degeneration observed in $\mathrm{ClC}-2 \mathrm{KO}$ mice (25). The degenerative phenotype in $\mathrm{ClC}-2 \mathrm{KO}$ mice is thought to be due to defective $\mathrm{Cl}^{-}$recycling for $\mathrm{Cl}^{-} / \mathrm{HCO}_{3}{ }^{-}$exchangers that may be needed to regulate the $\mathrm{pH}$ in the narrow extracellular clefts of these tissues, which depend heavily on lactate transport (25).

The improved survival of double-KO over CFTR KO mice (24) might be explained by an increased $\mathrm{Cl}^{-}$secretion (or less $\mathrm{Cl}^{-}$absorption) in ClC-2 $\mathrm{KO}$ colon, compatible with a basolateral instead of an apical localization of ClC-2 (24) (Figure 1A). ClC-2 has been variably reported to be present in apical $(26,27)$ or basolateral $(28,29)$ membranes of lung and intestinal epithelia. In $\mathrm{KO}$ controlled immunocytochemistry, $\mathrm{ClC}-2$ is exclusively detectable in basolateral membranes of surface epithelia of mouse colon, suggesting that it may be involved in $\mathrm{Cl}^{-}$absorption. It is not significantly expressed in deeper sites of crypts, where CFTR is expressed (10). These findings, and in particular the CFTR/ClC-2 double-KO mice (24), should put an end to speculations that ClC-2 activation may ameliorate the cystic fibrosis phenotype.

Both ClC-2 (30) and CFTR (31) are also expressed in the kidney, but their intrarenal expression pattern is poorly defined. No renal phenotype has been described for the ClC-2 KO mouse (25). Neither is there an overt renal pathology in cystic fibrosis (32), 
although CFTR may interact with ROMK (Kir1.1) $\mathrm{K}^{+}$channels and change their drug-sensitivity $(33,34)$ and was suggested to regulate $\mathrm{ENaC}$ in the kidney as well (35).

\section{ClC-K/barttin: basolateral chloride channels in kidney and inner ear epithelia}

The importance of the $\mathrm{Cl}^{-}$channels ClC-Ka/barttin (ClC-K1/barttin in rodents) and $\mathrm{ClC}-\mathrm{Kb} /$ barttin (ClC-K2/barttin in rodents) for the kidney, by contrast, is evident from their mutations in human genetic disease (36-38) and from a mouse model (39). Human lossof-function mutations in $\mathrm{ClC}-\mathrm{Kb}$ lead to severe renal salt loss in Bartter syndrome type III (36), whereas the disruption of ClC-K1 in mice causes a defect in urinary concentration (39). Human mutations in the common accessory $\beta$ subunit barttin lead to Bartter syndrome type IV, which combines severe renal salt loss with congenital deafness (40).

Like ClC-2, ClC-Ka and ClC-Kb are members of the CLC family of $\mathrm{Cl}^{-}$channels (41). They are $90 \%$ identical in their primary structure. Their genes are separated by just a few kilobases of DNA, indicating recent gene duplication. Both proteins are expressed in the kidney and the inner ear, as revealed by immunocytochemistry $(42,43)$ and the transgenic expression of a reporter gene driven by the $\mathrm{ClC}-\mathrm{Kb}$ promoter $(44,45)$. This showed that ClC-Ka is expressed in the thin limb of Henle loop of the nephron, whereas $\mathrm{ClC}-\mathrm{Kb}$ is present in the thick ascending limb of Henle loop and in the distal convoluted tubule, as well as in acid-transporting intercalated cells of the collecting duct. Also in the inner ear, $\mathrm{ClC}-\mathrm{Ka}$ and $\mathrm{ClC}-\mathrm{Kb}$ are expressed in epithelial cells. They are found in marginal cells of the stria vascularis and in dark cells of the vestibular organ, both of which probably coexpress these isoforms.

The high degree of amino acid identity between ClC-Ka and $\mathrm{ClC}-\mathrm{Kb}$ makes it difficult to generate isoform-specific antibodies, resulting in some uncertainty whether, for instance, the thick ascending limb or intercalated cells express both isoforms. The exclusive expression of ClC-K1 in the thin limb of Henle loop in the kidney, however, has been ascertained by the absence of staining in this segment in ClC-K1 KO mice (39). Immunocytochemistry suggests that $\mathrm{ClC}-\mathrm{K} 1$ and $\mathrm{ClC}-\mathrm{K} 2$ are expressed in basolateral membranes of renal $(42,43)$ and cochlear $(37)$ epithelia. The only exception might be the thin limb of Henle loop, where ClC-K1 was reported to be present in both apical and basolateral membranes by 1 group (42) but was found only in basolateral membranes by others (43). The $\beta$ subunit barttin was colocalized with $\mathrm{ClC}-\mathrm{K}$ in every tissue examined, e.g., in the thick ascending limb, the distal convoluted tubule, and intercalated cells of the kidney, as well as in inner ear epithelia (37). As yet, no cell or tissue has been identified that expresses barttin without a $\mathrm{ClC}-\mathrm{K}$ protein or vice versa.

Barttin, a rather small protein with 2 predicted transmembrane domains (40), is necessary for the functional expression of ClC-K currents (37). The only and enigmatic exception seems to be rat $\mathrm{ClC}-\mathrm{K} 1$, which yields plasma membrane currents also without barttin $(46,47)$. Coexpressing ClC-K1 with barttin, however, strongly increased currents (37) and diminished their sensitivity to extracellular $\mathrm{Ca}^{2+}$ (48). Barttin is necessary for the transport of ClC-K $\alpha$ subunits to the plasma membrane; this readily explains the stimulation of currents seen in coexpression (37). The cytoplasmic C-terminus of barttin contains a motif (PPYVRL) that is a potential site (PPY) for binding of WW domain-containing ubiquitin ligases, or that may serve as a tyrosine-based endocytosis signal (YVRL). Indeed, mutating the tyrosine led to a twofold increase in surface expression and currents (37). This is compatible with either hypothesis, as PY-dependent ubiquitination may serve as a signal for endocytosis as described for the epithelial $\mathrm{Na}^{+}$channel $\mathrm{ENaC}(49,50)$ or ClC-5 (51). It was reported that the ubiquitin ligase Nedd4-2 may mediate this effect (52). However, in contrast to findings for $\mathrm{ClC}-5$ (51) and $\mathrm{ENaC}$ (50), the expression of inactive forms of the WW domain-containing ubiquitin ligase did not increase $\mathrm{ClC}-\mathrm{K} /$ barttin currents (52). Taking into account the poor consensus sequence of the PY motif of barttin for WW domain binding, the reported interaction with Nedd 4 should be viewed with caution.

$\mathrm{ClC}-\mathrm{K} /$ barttin in salt reabsorption. The pathology of Bartter syndrome is easily understood in terms of a transport model for the thick ascending limb (Figure 1D), a nephron segment resorbing large amounts of $\mathrm{NaCl}$. Powered by the $\mathrm{Na}^{+}$gradient that is generated by the basolateral $\mathrm{Na}, \mathrm{K}-\mathrm{ATPase}$, the apical NaK2Cl cotransporter NKCC2 transports $\mathrm{Cl}^{-}$and $\mathrm{K}^{+}$into the cytoplasm. This raises $\left[\mathrm{Cl}^{-}\right]_{\mathrm{i}}$ above its electrochemical equilibrium, allowing for its diffusional, passive exit through basolateral ClC-Kb/barttin $\mathrm{Cl}^{-}$channels. $\mathrm{Na}^{+}$ions are transported across the basolateral membrane via the ATPase, while $\mathrm{K}^{+}$is recycled over the apical membrane via ROMK (Kir1.1) $\mathrm{K}^{+}$channels. This model is impressively supported by genetic evidence: mutations in NKCC2 underlie Bartter syndrome I (53); in ROMK, Bartter II (54); in ClC-Kb, Bartter III (36); and, finally, in barttin, Bartter IV (40).

$\mathrm{ClC}-\mathrm{K} /$ barttin in inner ear $\mathrm{K}^{+}$secretion. It is instructive to compare the renal thick ascending limb transport model (Figure 1D) with that of marginal cells of the cochlear stria vascularis (Figure 1C). The epithelium of the stria secretes $\mathrm{K}^{+}$into the fluid of the scala media of the cochlea. The exceptionally high $\mathrm{K}^{+}$concentration $(150 \mathrm{mM})$ and positive potential $(+100 \mathrm{mV})$ of this compartment are needed to provide the driving force for the depolarizing influx of $\mathrm{K}^{+}$through apical mechanosensitive ion channels of sensory hair cells and are hence essential for hearing (55). In marginal cells, the secretory, basolateral $\mathrm{NaK} 2 \mathrm{Cl}$ cotransporter isoform NKCC1, together with the Na,K-ATPase, raises cellular $\left[\mathrm{K}^{+}\right]$. Potassium then leaves the cell through apical $\mathrm{K}^{+}$ channels that are assembled from KCNQ1 and KCNE1 subunits. The $\mathrm{Na}^{+}$that is taken up together with $\mathrm{K}^{+}$is extruded via the ATPase, while cotransported $\mathrm{Cl}^{-}$ions must be recycled across the basolateral membrane. This occurs through basolateral ClC-Ka/barttin and $\mathrm{ClC}-\mathrm{Kb} /$ barttin $\mathrm{Cl}^{-}$channels, which are believed to be coexpressed in the stria (37). Again, this model is strongly supported by genetic evidence: mutations in either KCNQ1 (56) or KCNE1 (57) lead to deafness in Jervell and Lange-Nielsen syndrome. Disruption of NKCC1 in mice also causes deafness (58), as do mutations in barttin in Bartter syndrome type IV $(37,40)$. ClC- $K b$ mutations in Bartter III cause salt loss without deafness, because $\mathrm{ClC}-\mathrm{Kb} /$ barttin channels are rate-limiting in the thick ascending limb of the loop of Henle, but not in the stria, where their function can be replaced by $\mathrm{ClC}-\mathrm{Ka} /$ barttin. Only the disruption of the common $\beta$ subunit barttin results in a chloriderecycling defect that lowers strial $\mathrm{K}^{+}$secretion to pathogenic levels (37). This model has now been supported by the identification of a single family in which the disruption of both ClC-Ka and ClC-Kb results in a pathology indistinguishable from Bartter IV (59).

ClC-K/barttin: other potential roles. The function of $\mathrm{ClC}-\mathrm{K} /$ barttin in intercalated cells of the collecting duct, where it is expressed in both acid-secreting $\alpha$ and base-secreting $\beta$ cells (37), is less well understood. In $\alpha$ cells, it might serve to recycle $\mathrm{Cl}^{-}$for the basolateral $\mathrm{Cl}^{-} / \mathrm{HCO}_{3}{ }^{-}$exchanger $\mathrm{AE} 1$ (Figure $1 \mathrm{E}$ ). This role is also performed by the $\mathrm{K}-\mathrm{Cl}$ cotransporter $\mathrm{KCC} 4$, the disruption of which leads to renal tubular acidosis in mice (60). In the presence of the 
A

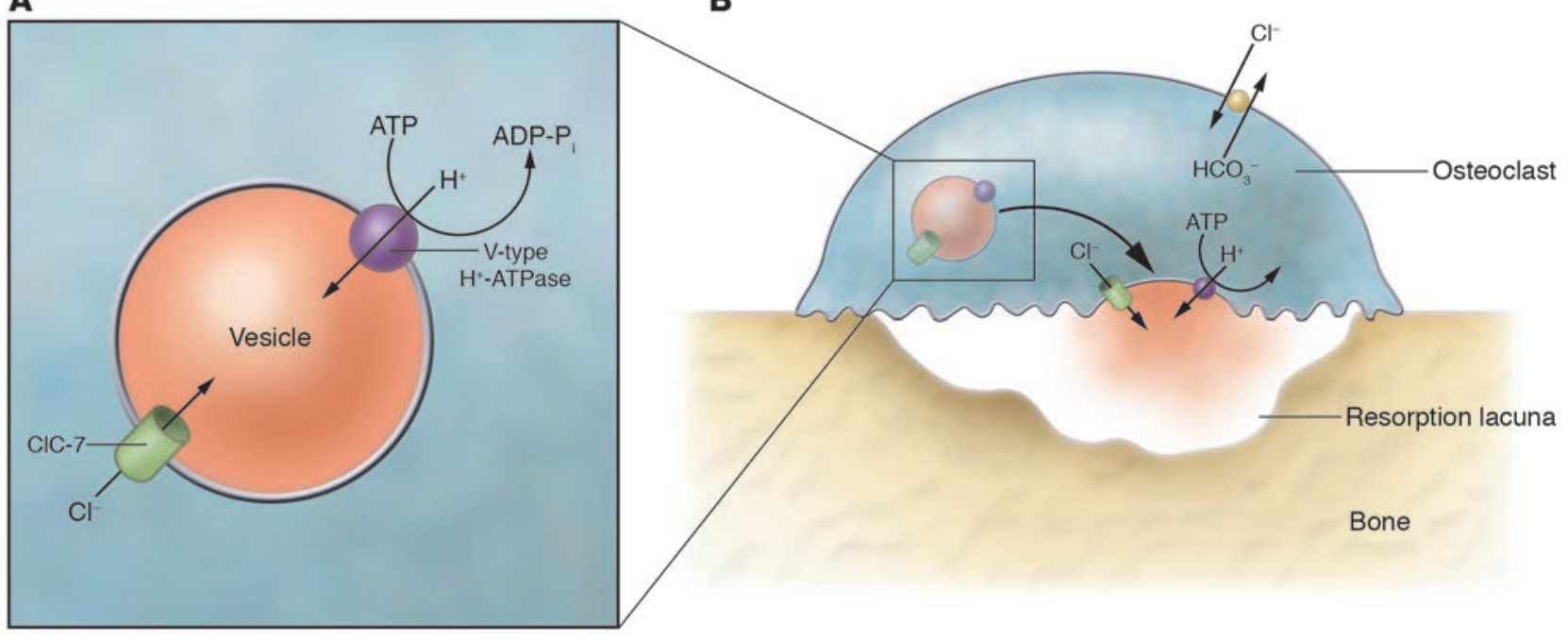

Figure 2

General concept of vesicular acidification exemplified by CIC-7. (A) Vesicles of the endosomal and lysosomal pathway are acidified by $\mathrm{H}^{+}$-ATPases. Their current is neutralized by $\mathrm{Cl}^{-}$channels. In their absence, efficient proton pumping is prevented. (B) Model for the resorption lacuna acidification in osteoclasts. The $\mathrm{H}^{+}$-ATPase and CIC-7 are trafficked to the "ruffled border" membrane of osteoclasts. The acidification of the resorption lacuna is required for dissolving the mineral phase of bone, as well as for the enzymatic degradation of the organic bone matrix by lysosomal enzymes. It depends on the presence of both CIC-7 and the $\mathrm{H}^{+}$-ATPase in the ruffled border.

severe disturbance of renal salt handling in Bartter patients, an additional distal acidification defect may not be easily detectable.

Interestingly, there is a common polymorphism in the human gene encoding $C l C-K b$. It exchanges a threonine for serine at position 481 before helix P. T481S mutant channels show dramatically increased currents when expressed in oocytes (61). If currents through $\mathrm{ClC}-\mathrm{Kb} /$ barttin were rate-limiting for $\mathrm{NaCl}$ reabsorption in the thick ascending limb or distal convoluted tubule, this polymorphism could lead to increased salt reabsorption and possibly hypertension. Indeed, a statistical association of the T481S variant with hypertension was described (62). However, as with other association studies, firm conclusions may only be drawn after these results have been replicated in other cohorts (63). A recent study did not find a correlation between the T481S polymorphism and high blood pressure in the Japanese population, in which, however, the frequency of this polymorphism was only about 3\% (64).

Human mutations in ClC-Ka alone have not yet been reported. The targeted disruption of the mouse homolog ClC-K1 leads to a diabetes insipidus-like phenotype (39). This mouse model demonstrates that the large $\mathrm{Cl}^{-}$conductance in the thin limb, which is part of the countercurrent system, is essential for solute accumulation in the inner renal medulla (65).

\section{Vesicular chloride channels}

Ion channels are present not only in the plasma membrane, but also in membranes of intracellular organelles like vesicles of the endocytotic or secretory pathways, synaptic vesicles, the endoplasmic and sarcoplasmic reticulum, or mitochondria. With the exception of intracellular $\mathrm{Ca}^{2+}$ channels or anion channels of mitochondria, they have received much less attention than plasma membrane channels. This is probably in part due to the experimental difficulties involved in their study. Recent genetic evidence on the role of vesicular CLC gene family $\mathrm{Cl}^{-}$channels, however, has revealed their great physiological importance.
While $\mathrm{ClC}-1,-2$, $-\mathrm{Ka}$, and $-\mathrm{Kb}$ form the branch of CLC channels that reside predominantly in plasma membranes, ClC-3, -4, -5, -6, and -7 are located mainly in vesicles of the endocytotic and lysosomal pathway. As a word of caution, one should acknowledge the possibility that some of these proteins might not be channels, but $\mathrm{Cl}^{-} / \mathrm{H}^{+}$ exchangers similar to the bacterial homolog ClC-e1 (3). Within this second group, ClC-3, - 4 , and -5 form a separate homology branch of closely related proteins displaying $80 \%$ sequence identity.

Most intracellular organelles on which CLC channels have been found are acidified by vesicular $\mathrm{H}^{+}$-ATPases. $\mathrm{H}^{+}$transport unbalanced by a parallel $\mathrm{Cl}^{-}$current would generate a lumen-positive potential ultimately preventing further acidification. Hence, vesicular CLC proteins are thought to facilitate vesicular acidification (Figure 2A).

\section{ClC-5, endocytosis, and Dent disease}

Within this branch, the function of $\mathrm{ClC}-5$ is best understood, as mutations in its gene cause a renal disorder, Dent disease (66). This rare $\mathrm{X}$-linked disease is characterized by low-molecular weight proteinuria that is in most cases accompanied by hypercalciuria, nephrolithiasis, nephrocalcinosis, and sometimes renal failure (67). The link between chloride channel function and the complex disease pathology has been established mainly through the use of KO mouse models (68-70).

The kidney is the major site of ClC-5 expression, followed by the intestine $(71,72)$. ClC-5 is most prominently expressed in the proximal tubule (PT) and in intercalated cells of the collecting duct, with significantly lower levels also being present in other segments like the thick ascending limb (68-70). While the function of ClC-5 in acid-transporting intercalated cells is not yet clear, its role in PTs has been resolved in considerable detail. The PT is responsible for the endocytotic uptake of low-molecular weight proteins that have passed the glomerular filter. Immunofluorescence revealed a rim stained for $\mathrm{ClC}-5$ right underneath the brush border of the proximal tubular cells that colocalized with the V-type ATPase $(68,70)$. 
A
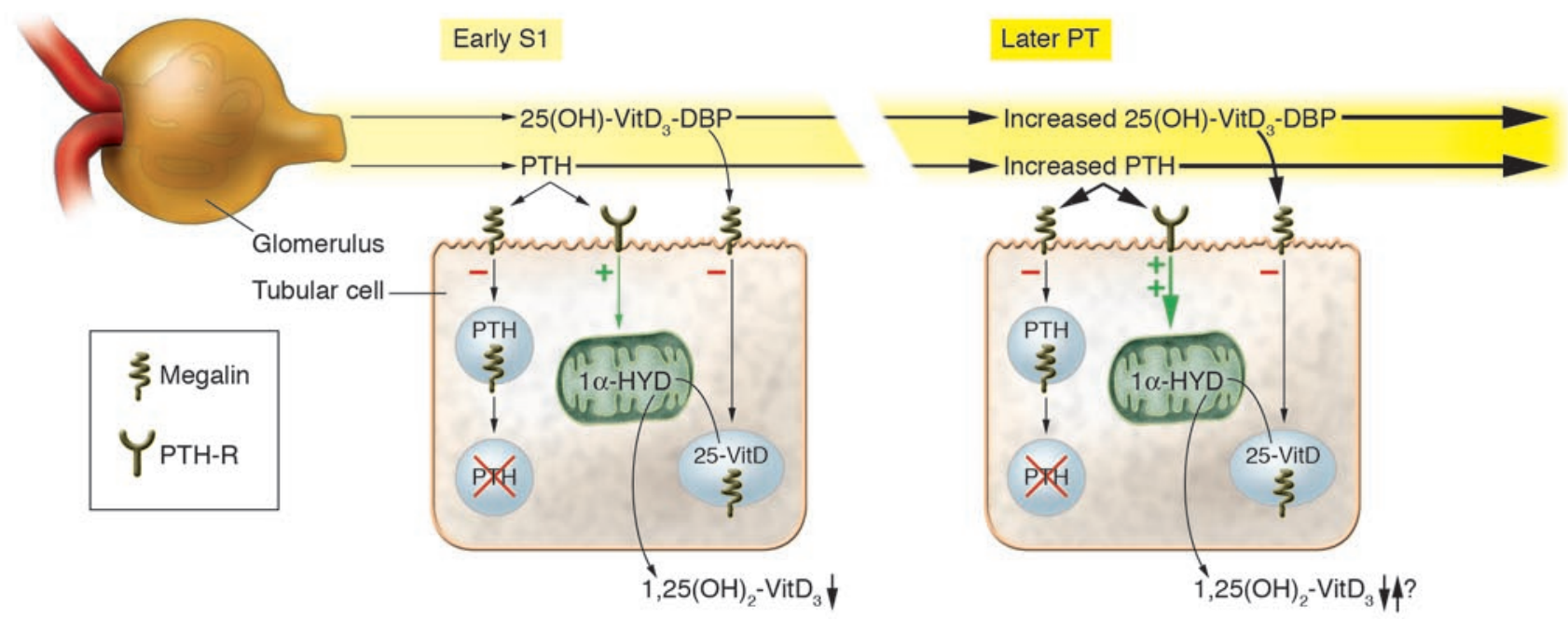

B
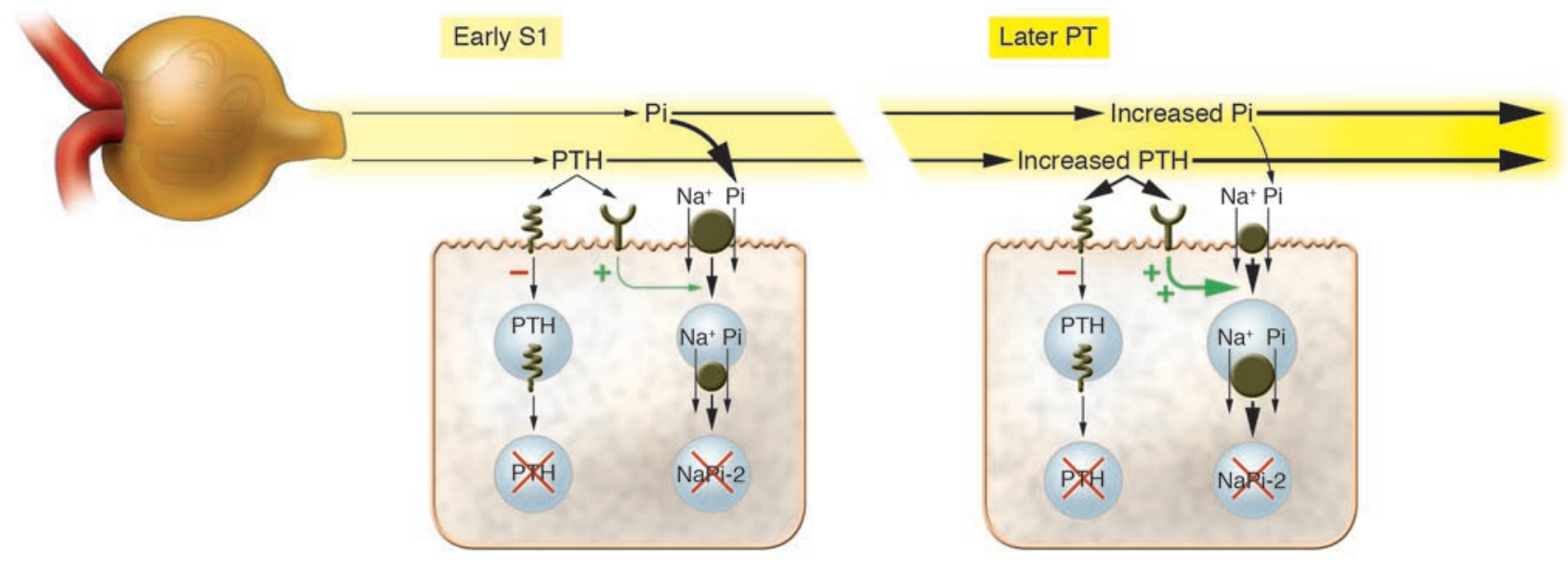

Figure 3

Model to explain hypercalciuria and hyperphosphaturia in Dent disease. (A) Alterations in vitamin D metabolism. Parathyroid hormone (PTH) is filtered into the primary urine from which it is normally cleared by megalin-mediated endocytosis and subsequent degradation. The impaired endocytosis due to a disruption of CIC-5 results in an increased luminal PTH concentration that leads to an enhanced activation of luminal PTH receptors (PTH-R). This stimulates the transcription of the mitochondrial enzyme $1 \alpha$-hydroxylase (1 $\alpha$-HYD) that catalyzes the conversion of the vitamin D precursor $25(\mathrm{OH})-\mathrm{Vit}_{3}$ into the active metabolite $1,25(\mathrm{OH})_{2}-\mathrm{Vit}_{3}$. Increased enzyme activity would be expected to lead to an increased production of $1,25(\mathrm{OH})_{2}-\mathrm{VitD}_{3}$ that in turn would indirectly cause hypercalciuria by stimulating intestinal $\mathrm{Ca}^{2+}$ reabsorption. However, $25(\mathrm{OH})-\mathrm{Vit} \mathrm{D}_{3}$ (bound to its binding protein DBP) is mainly taken up apically by megalin- and CIC-5-dependent endocytosis. Hence, the endocytosis defect in Dent disease leads to a decreased availability of the substrate for $1 \alpha-H Y D$. Thus there is a delicate balance between enzyme activation and precursor scarcity that can turn toward decreased as well as increased production of $1,25(\mathrm{OH})_{2}-\mathrm{VitD}_{3}$. Furthermore, the active hormone is also lost into the urine. This may account for the variability of hypercalciuria observed in Dent disease patients as well as in CIC-5 KO mouse models. (B) Mechanism causing phosphaturia. The apical Na phosphate cotransporter NaPi-2a is regulated by PTH, which causes its endocytosis and degradation. The increased stimulation of apical PTH receptors that is due to the increased luminal PTH concentration caused by an impaired endocytosis of PTH in the absence of $\mathrm{CIC}-5$ leads to less NaPi-2a in the apical membrane, resulting in a urinary loss of phosphate.

Immune electron microscopy confirmed its presence in this subapical region that is packed with endocytotic vesicles (68). When the uptake of labeled protein into proximal tubular cells was analyzed, ClC-5 colocalized with the endocytosed material only at early time points, arguing for its presence on early endosomes (68). This subcellular localization of $\mathrm{ClC}-5$ points to an involvement in early endocytosis, which is obviously consistent with the proteinuria observed in Dent disease. Endosomes are acidified by a V-type ATPase that needs a counter-ion flux for effective operation (Figure 2A). Otherwise the electrogenic influx of protons into the vesicle would soon create a membrane potential that would hinder further proton pumping and thus prevent the creation of a large $\mathrm{pH}$ gradient. This counter-ion flux was suggested to be chloride. On the basis of these data, it was suggested that $\mathrm{ClC}-5$, because it facilitated endosome acidification, was essential for renal endocytosis (68).

This hypothesis was fully confirmed by ClC-5 KO mouse models (68-70). The elimination of ClC-5 reproduced the low-molecular weight proteinuria observed in patients. The loss of $\mathrm{ClC}-5$ drastically reduced apical fluid-phase and receptor-mediated endocytosis, as well as the retrieval of apical membrane proteins, in a cell-autono- 
mous manner (73). The in vitro acidification of cortical renal endosomes prepared from ClC-5 $\mathrm{KO}$ animals was significantly reduced, which strongly supports the postulated role of $\mathrm{ClC}-5$ in endosomal acidification $(73,74)$. Several studies have shown that interfering with endosomal acidification impairs endocytosis (75). A link between these processes might be provided by a $\mathrm{pH}$-dependent association of regulatory proteins like Arf6 (76) with endosomes. However, this aspect has not been fully resolved yet, and other regulators of endocytosis such as rab GTPases were found to be unchanged in $\mathrm{ClC}-5 \mathrm{KO}$ mice (77). The expression of the endocytotic receptor megalin was decreased in a cell-autonomous manner in PT cells lacking ClC-5; this suggests a defect in recycling megalin back to the surface (73). This was later confirmed by an electron microscopic study that also revealed a reduction of the coreceptor cubilin (77). The decrease of these endocytotic receptors, which show broad substrate specificity, is expected to lead to a further impairment of receptor-mediated endocytosis. The importance of megalin can be gleaned from megalin $\mathrm{KO}$ mice, whose renal phenotype resembles in many respects that of ClC-5 $\mathrm{KO}$ mice (78).

Hypercalciuria and byperphosphaturia: a consequence of impaired endocytosis. It is likely that the most important function of proximal tubular endocytosis is the conservation of essential vitamins like vitamin D or retinol (79) that are reabsorbed in the PT in a megalindependent process together with their respective binding proteins. Whereas these binding proteins, like the vast majority of other endocytosed proteins, are degraded in lysosomes, the attached vitamins are recycled into the blood or are even processed to the active hormone in the PT (vitamin D). The disruption of ClC-5, like that of megalin $(80,81)$, led to a massive loss of retinol and vitamin $\mathrm{D}$, as well as their binding proteins, into the urine $(73,74)$.

Both Dent disease patients and ClC-5 KO mice lose vitamin D and its metabolites into the urine. The situation is, however, complex because of the influence of parathyroid hormone on vitamin $\mathrm{D}$ metabolism. Parathyroid hormone enhances the production of 1,25-dihydroxyvitamin $\mathrm{D}_{3}\left[1,25(\mathrm{OH})_{2}-\mathrm{Vit}_{3}\right]$ in proximal tubular cells by stimulating the transcription of the enzyme $1 \alpha$-hydroxylase that converts the inactive precursor $25(\mathrm{OH})-\mathrm{Vit}_{3}$ into the active hormone. Being a small-peptide hormone, parathyroid hormone is freely filtered into the urine from which it is normally endocytosed by proximal tubular cells in a megalin-dependent manner (82). As predicted, parathyroid hormone concentration is elevated in the urine of ClC-5 KO mice (73) and of patients with Dent disease (83). This implies that a disruption of $\mathrm{ClC}-5$ causes an increase in the concentration of parathyroid hormone along the length of the PT (73). In proximal tubular cells, parathyroid hormone receptors are found not only in basolateral but also in apical membranes. The increased stimulation of apical receptors by the elevated parathyroid hormone concentration then stimulates the transcription of $1 \alpha$-hydroxylase and results in an increased ratio of serum $1,25(\mathrm{OH})_{2}-\mathrm{VitD}_{3}$ to $25(\mathrm{OH})-\mathrm{VitD}_{3}$ in the $\mathrm{KO}(73,74)$ (Figure $\left.3 \mathrm{~A}\right)$. This, however, does not necessarily raise the absolute serum concentration of the active hormone $1,25(\mathrm{OH})_{2}-\mathrm{VitD}_{3}$, because the lack of ClC-5 severely reduces the uptake of the precursor $25(\mathrm{OH})-\mathrm{VitD}_{3}$ into proximal tubular cells. It seems that the balance between these 2 effects can turn in either direction, possibly depending on dietary or genetic factors. In most patients, serum vitamin $\mathrm{D}$ is slightly increased $(67,84)$, whereas it is consistently decreased in our KO mouse model (73). Elevated levels of $1,25(\mathrm{OH})_{2}-\mathrm{VitD}_{3}$ are expected to stimulate the intestinal absorption of calcium, which may then be excreted in increased amounts by the kidney, resulting in hypercalciuria. However, using a ClC-5 KO mouse model that displays hypercalciuria (85) and increased levels of serum $1,25(\mathrm{OH})_{2}-\mathrm{VitD}_{3}$, Silva et al. (86) suggest that the hypercalciuria is rather of bone and renal origin instead of being caused by increased intestinal calcium absorption. This was in part supported by elevated bone-turnover markers in the $\mathrm{KO}$ mice.

The hyperphosphaturia found in Dent disease also appears to be a secondary effect of the increased urinary parathyroid hormone concentration (Figure $3 \mathrm{~B}$ ). Phosphate reabsorption in the PT occurs mainly through $\mathrm{NaPi}-2 \mathrm{a}$. This $\mathrm{Na}^{+}$phosphate cotransporter is downregulated by parathyroid hormone via endocytosis and lysosomal degradation (87). As expected from the increase in luminal parathyroid hormone, the amount of NaPi-2a was decreased in $\mathrm{ClC}-5 \mathrm{KO}$ mice, and the protein was mainly found in intracellular vesicles (73). This fully explains the observed hyperphosphaturia in terms of a primary defect in endocytosis of parathyroid hormone.

More than 30 different human mutations in ClC-5 are known to cause Dent disease. When investigated in heterologous expression, most of them reduce or abolish ClC-5 currents $(66,88-90)$. Recently, it has been suggested that Dent disease might be genetically heterogeneous (91), and OCRL1 was identified as a second gene that is mutated in some Dent disease patients (92). This gene encodes phosphatidylinositol 4,5-bisphosphate-( $\left.\mathrm{PIP}_{2}\right)$-5-phosphatase, which had been known to be mutated in the multisystem disease Lowe syndrome. This finding is consistent with a role of phosphatidylinositol metabolites in endocytotic trafficking.

\section{ClC-3: disruption leads to neurodegeneration}

No human disease with mutations in $\mathrm{ClC}-3$ has been reported so far, but in mice, the disruption of this channel leads to a severe neurodegeneration with a dramatic loss of the hippocampus and the retina (93). ClC-3 is located on synaptic vesicles and endosomes (93). Its disruption impairs the acidification of these compartments (93-95).

\section{ClC-7: role in osteopetrosis}

A KO mouse model led to the discovery that another vesicular $\mathrm{Cl}^{-}$channel, ClC-7, is mutated in human osteopetrosis (96). ClC-7 displays a very broad tissue distribution and is expressed in late endosomes and lysosomes. Its disruption in mice led to severely sick animals that died about 6 weeks after birth and displayed the typical hallmarks of osteopetrosis, as well as a rapidly progressing retinal degeneration (96). ClC-7 KO mice also display neurodegeneration in the CNS (97). In agreement with the lysosomal localization of ClC-7, it displays characteristics typical for lysosomal storage diseases. Electron microscopy revealed storage material reminiscent of neuronal ceroid lipofuscinosis. Interestingly, storage material was also observed in the PT, where protein turnover is high (97). Skeletal abnormalities included the loss of bone marrow cavities that were instead filled by bone material, as well as a failure of teeth to erupt. ClC-7 is highly expressed in osteoclasts (96), the cells involved in bone degradation. It localizes to the acid-secreting ruffled border, which is formed by the exocytotic insertion of $\mathrm{H}^{+}$-ATPase-containing vesicles of late endosomal/ lysosomal origin. It was suggested that $\mathrm{ClC}-7$ is co-inserted with the $\mathrm{H}^{+}$-ATPase into this membrane and serves, like $\mathrm{ClC}-5$ in endosomes, as a shunt for the acidification of the resorption lacuna (Figure 2B). This acidification is crucial for the chemical dissolution of inorganic bone material, as well as for the activity of cosecreted lysosomal enzymes that degrade the organic bone matrix. 
In a culture system, ClC-7 $\mathrm{KO}$ osteoclasts still attached to ivory but failed to acidify the resorption lacuna and were unable to degrade the bone surrogate (96).

The mouse pathology suggested that ClC-7 might also underlie recessive malignant infantile human osteopetrosis, and indeed ClC-7 mutations were identified in such patients (96). By now, about 30 human ClC-7 mutations are known to cause human osteopetrosis. Interestingly, this includes mutations found in autosomal dominant osteopetrosis of the Albers-Schönberg type (98). These mutations are present in a heterozygous state and presumably exert a dominant-negative effect on the coexpressed product of the normal allele. The situation is thus similar to findings with the skeletal muscle chloride channel ClC-1, mutations in which can cause recessive or dominant myotonia $(99,100)$. Because of the dimeric structure of CLC channels, about $25 \%$ of normal channel function should be left upon a 1:1 coexpression of dominantnegative and WT alleles. Hence, osteopetrosis in Albers-Schönberg disease is less severe, needs several years to decades to develop, and is usually not associated with blindness.

\section{Conclusions}

Our understanding of the physiological functions of chloride channels has been greatly advanced by mouse models and human diseases. The resulting pathologies have also yielded novel insights into vesicular chloride channels, disruption of which yields pathologies as diverse as proteinuria and osteopetrosis. This finally puts vesicular channels, which have received much less attention than plasma membrane channels, into the limelight.

Note added in proof. $\mathrm{ClC}-4$ and $\mathrm{ClC}-5$ were recently shown to be electrogenic $\mathrm{Cl}^{-} / \mathrm{H}^{+}$antiporters rather than channels $(101,102)$. This very likely also applies to the highly homologous $\mathrm{ClC}-3$. Such an exchange activity is also compatible with their role in vesicular acidification.

Address correspondence to: Thomas J. Jentsch, Zentrum für Molekulare Neurobiologie Hamburg, ZMNH, Universität Hamburg, Falkenried 94, D-20252 Hamburg, Germany. Phone: 49-40-42803-4741; Fax: 49-40-42803-4839; E-mail: Jentsch@zmnh.uni-hamburg.de.
1. Hübner, C., et al. 2001. Disruption of KCC2 reveals an essential role of $\mathrm{K}-\mathrm{Cl}$ cotransport already in early synaptic inhibition. Neuron. 30:515-524.

2. Riordan, J.R., et al. 1989. Identification of the cystic fibrosis gene: cloning and characterization of complementary DNA. Science. 245:1066-1073.

3. Accardi, A., and Miller, C. 2004. Secondary active transport mediated by a prokaryotic homologue of $\mathrm{ClC} \mathrm{Cl}^{-}$channels. Nature. 427:803-807.

4. Stutts, M.J., et al. 1995. CFTR as a cAMP-dependent regulator of sodium channels. Science. 269:847-850.

5. Reddy, M.M., Light, M.J., and Quinton, P.M. 1999. Activation of the epithelial $\mathrm{Na}^{+}$channel $(\mathrm{ENaC})$ requires CFTR Cl- channel function. Nature. 402:301-304.

6. Nagel, G., Szellas, T., Riordan, J.R., Friedrich, T., and Hartung, K. 2001. Non-specific activation of the epithelial sodium channel by the CFTR chloride channel. EMBO Rep. 2:249-254.

7. Mall, M., Grubb, B.R., Harkema, J.R., O’Neal, W.K., and Boucher, R.C. 2004. Increased airway epithelial $\mathrm{Na}^{+}$absorption produces cystic fibrosis-like lung disease in mice. Nat. Med. 10:487-493.

8. Nagel, G., Szellas, T., Riordan, J.R., Friedrich, T., and Hartung, K. 2001. Non-specific activation of the epithelial sodium channel by the CFTR chloride channel. EMBO Rep. 2:249-254.

9. Ko, S.B., et al. 2004. Gating of CFTR by the STAS domain of SLC26 transporters. Nat. Cell Biol. 6:343-350

10. Strong, T.V., Boehm, K., and Collins, F.S. 1994. Localization of cystic fibrosis transmembrane conductance regulator mRNA in the human gastrointestinal tract by in situ hybridization. J. Clin. Invest. 93:347-354.

11. Welsh, M.J., Smith, P.L., Fromm, M., and Frizzell, R.A. 1982. Crypts are the site of intestinal fluid and electrolyte secretion. Science. 218:1219-1221.

12. Schroeder, B.C., et al. 2000. A constitutively open potassium channel formed by KCNQ1 and KCNE3. Nature. 403:196-199.

13. Dedek, K., and Waldegger, S. 2001. Colocalization of KCNQ1/KCNE channel subunits in the mouse gastrointestinal tract. Pflügers Arch. 442:896-902.

14. Clarke, L.L., et al. 1992. Defective epithelial chloride transport in a gene-targeted mouse model of cystic fibrosis. Science. 257:1125-1128.

15. Rufo, P.A., et al. 1997. The antifungal antibiotic, clotrimazole, inhibits chloride secretion by human intestinal T84 cells via blockade of distinct basolateral $\mathrm{K}^{+}$conductances. Demonstration of efficacy in intact rabbit colon and in an in vivo mouse model of cholera. J. Clin. Invest. 100:3111-3120.

16. Salvatore, F., Scudiero, O., and Castaldo, G. 2002. Genotype-phenotype correlation in cystic fibrosis: the role of modifier genes. Am. J. Med. Genet. 111:88-95.

17. Bronsveld, I., et al. 2001. Chloride conductance and genetic background modulate the cystic fibrosis phenotype of Delta F508 homozygous twins and siblings. J. Clin. Invest. 108:1705-1715. doi:10.1172/ JCI200112108.

18. Rozmahel, R., et al. 1996. Modulation of disease severity in cystic fibrosis transmembrane conductance regulator deficient mice by a secondary genetic factor. Nat. Genet. 12:280-287.

19. Gyömörey, K., Rozmahel, R., and Bear, C.E. 2000. Amelioration of intestinal disease severity in cystic fibrosis mice is associated with improved chloride secretory capacity. Pediatr. Res. 48:731-734.

20. Ritzka, M., et al. 2004. The CLCA gene locus as a modulator of the gastrointestinal basic defect in cystic fibrosis. Hum. Genet. 115:483-491.

21. Gyömörey, K., Yeger, H., Ackerley, C., Garami, E., and Bear, C.E. 2000. Expression of the chloride channel ClC-2 in the murine small intestine epithelium. Am. J. Physiol. Cell Physiol. 279:C1787-C1794.

22. Schwiebert, E.M., et al. 1998. Analysis of ClC-2 channels as an alternative pathway for chloride conduction in cystic fibrosis airway cells. Proc. Natl. Acad. Sci. U. S. A. 95:3879-3884.

23. Blaisdell, C.J., Pellettieri, J.P., Loughlin, C.E., Chu, S., and Zeitlin, P.L. 1999. Keratinocyte growth factor stimulates CLC-2 expression in primary fetal rat distal lung epithelial cells. Am. J. Respir. Cell Mol. Biol. 20:842-847.

24. Zdebik, A.A., Cuffe, J., Bertog, M., Korbmacher, C., and Jentsch, T.J. 2004. Additional disruption of the ClC-2 $\mathrm{Cl}^{-}$channel does not exacerbate the cystic fibrosis phenotype of CFTR mouse models. J. Biol. Chem. 279:22276-22283.

25. Bösl, M.R., et al. 2001. Male germ cells and photoreceptors, both depending on close cell-cell interactions, degenerate upon $\mathrm{ClC}-2 \mathrm{Cl}^{-}$-channel disruption. EMBO J. 20:1289-1299.

26. Mohammad-Panah, R, et al. 2001. ClC-2 contributes to native chloride secretion by a human intestinal cell line, Caco-2. J. Biol. Chem. 276:8306-8313.

27. Murray, C.B., et al. 1995. CIC-2: a developmentally dependent chloride channel expressed in the fetal lung and downregulated after birth. Am. J. Respir. Cell Mol. Biol. 12:597-604.

28. Lipecka, J., et al. 2002. Distribution of ClC-2 chlo- ride channel in rat and human epithelial tissues. Am. J. Physiol. Cell Physiol. 282:C805-C816.

29. Catalán, M., Niemeyer, M.I., Cid, L.P., and Sepúlveda, F.V. 2004. Basolateral ClC-2 chloride channels in surface colon epithelium: regulation by a direct effect of intracellular chloride. Gastroenterology. 126:1104-1114.

30. Thiemann, A., Gründer, S., Pusch, M., and Jentsch, T.J. 1992. A chloride channel widely expressed in epithelial and non-epithelial cells. Nature. 356:57-60.

31. Crawford, I., et al. 1991. Immunocytochemical localization of the cystic fibrosis gene product CFTR. Proc. Natl. Acad. Sci. U. S. A. 88:9262-9266.

32. Gibney, E.M., and Goldfarb, D.S. 2003. The association of nephrolithiasis with cystic fibrosis. Am. J. Kidney Dis. 42:1-11.

33. McNicholas, C.M., et al. 1996. Sensitivity of a renal $\mathrm{K}^{+}$channel (ROMK2) to the inhibitory sulfonylurea compound glibenclamide is enhanced by coexpression with the ATP-binding cassette transporter cystic fibrosis transmembrane regulator. Proc. Natl. Acad. Sci. U. S. A. 93:8083-8088.

34. Yoo, D., et al. 2004. Assembly and trafficking of a multiprotein ROMK (Kir 1.1) channel complex by PDZ interactions. J. Biol. Chem. 279:6863-6873.

35. Kibble, J.D., Neal, A.M., Colledge, W.H., Green, R., and Taylor, C.J. 2000. Evidence for cystic fibrosis transmembrane conductance regulatordependent sodium reabsorption in kidney, using Cftr(tm2cam) mice. J. Physiol. 526:27-34.

36. Simon, D.B., et al. 1997. Mutations in the chloride channel gene, $C L C N K B$, cause Bartter's syndrome type III. Nat. Genet. 17:171-178.

37. Estévez, R., et al. 2001. Barttin is a $\mathrm{Cl}^{-}$-channel $\beta$-subunit crucial for renal $\mathrm{Cl}^{-}$-reabsorption and inner ear $\mathrm{K}^{+}$-secretion. Nature. 414:558-561.

38. Birkenhäger, R., et al. 2001. Mutation of BSND causes Bartter syndrome with sensorineural deafness and kidney failure. Nat. Genet. 29:310-314.

39. Matsumura, Y., et al. 1999. Overt nephrogenic diabetes insipidus in mice lacking the CLC-K1 chloride channel. Nat. Genet. 21:95-98.

40. Birkenhäger, R., et al. 2001. Mutation of BSND causes Bartter syndrome with sensorineural deafness and kidney failure. Nat. Genet. 29:310-314.

41. Jentsch, T.J., Stein, V., Weinreich, F., and Zdebik, A.A. 2002. Molecular structure and physiological function of chloride channels. Physiol. Rev. 82:503-568.

42. Uchida, S., et al. 1995. Localization and functional characterization of rat kidney-specific chloride 
channel, ClC-K1. J. Clin. Invest. 95:104-113.

43. Vandewalle, A., et al. 1997. Localization and induction by dehydration of ClC-K chloride channels in the rat kidney. Am. J. Physiol. 272:F678-F688.

44. Kobayashi, K., Uchida, S., Okamura, H.O., Marumo, F., and Sasaki, S. 2002. Human CLC-KB gene promoter drives the EGFP expression in the specific distal nephron segments and inner ear. J. Am. Soc. Nephrol. 13:1992-1998.

45. Maehara, H., et al. 2003. Expression of CLC-KB gene promoter in the mouse cochlea. Neuroreport. 14:1571-1573.

46. Uchida, S., et al. 1993. Molecular cloning of a chloride channel that is regulated by dehydration and expressed predominantly in kidney medulla [erratum 1994, 269:19192]. J. Biol. Chem. 268:3821-3824.

47. Waldegger, S., and Jentsch, T.J. 2000. Functional and structural analysis of $\mathrm{ClC}-\mathrm{K}$ chloride channels involved in renal disease. J. Biol. Chem. 275:24527-24533.

48. Waldegger, S., et al. 2002. Barttin increases surface expression and changes current properties of $\mathrm{ClC}-\mathrm{K}$ channels. Pflügers Arch. 444:411-418.

49. Staub, O., et al. 1996. WW domains of Nedd4 bind to the proline-rich PY motifs in the epithelial Na channel deleted in Liddle's syndrome. EMBO J 15:2371-2380.

50. Abriel, H., et al. 1999. Defective regulation of the epithelial $\mathrm{Na}^{+}$channel by Nedd4 in Liddle's syndrome. J. Clin. Invest. 103:667-673.

51. Schwake, M., Friedrich, T., and Jentsch, T.J. 2001. An internalization signal in $\mathrm{ClC}-5$, an endosomal $\mathrm{Cl}^{-}$-channel mutated in Dent's disease. J. Biol. Chem. 276:12049-12054.

52. Embark, H.M., et al. 2004. Regulation of CLC$\mathrm{Ka} /$ barttin by the ubiquitin ligase Nedd4-2 and the serum- and glucocorticoid-dependent kinases. Kidney Int. 66:1918-1925.

53. Simon, D.B., et al. 1996. Bartter's syndrome, hypokalaemic alkalosis with hypercalciuria, is caused by mutations in the $\mathrm{Na}-\mathrm{K}-2 \mathrm{Cl}$ cotransporter NKCC2 Nat. Genet. 13:183-188.

54. Simon, D.B., et al. 1996. Genetic heterogeneity of Bartter's syndrome revealed by mutations in the $\mathrm{K}^{+}$ channel, ROMK. Nat. Genet. 14:152-156.

55. Jentsch, T.J. 2000. Neuronal KCNQ channel: physiology and role in disease. Nat. Rev. Neurosci. 1:21-30.

56. Neyroud, N., et al. 1997. A novel mutation in the potassium channel gene KVLQT1 causes the Jervell and Lange-Nielsen cardioauditory syndrome. Nat. Genet. 15:186-189.

57. Schulze-Bahr, E., et al. 1997. KCNE1 mutations cause Jervell and Lange-Nielsen syndrome. Nat. Genet. 17:267-268.

58. Delpire, E., Lu, J., England, R., Dull, C., and Thorne, T. 1999. Deafness and imbalance associated with inactivation of the secretory $\mathrm{Na}-\mathrm{K}-2 \mathrm{Cl}$ co-transporter. Nat. Genet. 22:192-195.

59. Schlingmann, K.P., et al. 2004. Salt wasting and deafness resulting from mutations in two chloride channels. N. Engl. J. Med. 350:1314-1319.

60. Boettger, T., et al. 2002. Deafness and renal tubular acidosis in mice lacking the $\mathrm{K}-\mathrm{Cl}$ cotransporter Kcc4. Nature. 416:874-878.

61. Jeck, N., Waldegger, P., Doroszewicz, J., Seyberth, H., and Waldegger, S. 2004. A common sequence variation of the $C L C N K B$ gene strongly activates $\mathrm{ClC}-\mathrm{Kb}$ chloride channel activity. Kidney Int 65:190-197.

62. Jeck, N., et al. 2004. Activating mutation of the renal epithelial chloride channel ClC-Kb predisposing to hypertension. Hypertension. 43:1175-1181.

63. Geller, D.S. 2004. A genetic predisposition to hypertension? Hypertension. 44:27-28.

64. Kokubo, Y., et al. 2005. Association analysis between hypertension and CYBA, CLCNKB, and $K C N M B 1$ functional polymorphisms in the Japanese population. Circ. J. 69:138-142.

65. Akizuki, N., Uchida, S., Sasaki, S., and Marumo, F. 2001. Impaired solute accumulation in inner medulla of Clcnk $1^{-/-}$mice kidney. Am. J. Physiol. 280:F79-F87.

66. Lloyd, S.E., et al. 1996. A common molecular basis for three inherited kidney stone diseases. Nature. 379:445-449.

67. Wrong, O.M., Norden, A.G., and Feest, T.G. 1994 Dent's disease: a familial proximal renal tubular syndrome with low-molecular-weight proteinuria, hypercalciuria, nephrocalcinosis, metabolic bone disease, progressive renal failure and a marked male predominance. OJM. 87:473-493.

68. Günther, W., Lüchow, A., Cluzeaud, F., Vandewalle, A., and Jentsch, T.J. 1998. ClC-5, the chloride channel mutated in Dent's disease, colocalizes with the proton pump in endocytotically active kidney cells. Proc. Natl. Acad. Sci. U. S. A. 95:8075-8080.

69. Devuyst, O., Christie, P.T., Courtoy, P.J., Beauwens, R., and Thakker, R.V. 1999. Intra-renal and subcellular distribution of the human chloride channel, CLC-5, reveals a pathophysiological basis for Dent's disease. Hum. Mol. Genet. 8:247-257.

70. Sakamoto, H., et al. 1999. Cellular and subcellular immunolocalization of ClC-5 channel in mouse kidney: colocalization with $\mathrm{H}^{+}$-ATPase. Am. J. Physiol. 277:F957-F965.

71. Fisher, S.E., et al. 1994. Isolation and partial characterization of a chloride channel gene which is expressed in kidney and is a candidate for Dent's disease (an X-linked hereditary nephrolithiasis). Hum. Mol. Genet. 3:2053-2059.

72. Steinmeyer, K., Schwappach, B., Bens, M., Vandewalle, A., and Jentsch, T.J. 1995. Cloning and functional expression of rat CLC-5, a chloride channel related to kidney disease. J. Biol. Chem. 270:31172-31177

73. Piwon, N., Günther, W., Schwake, R., Bösl, M.R., and Jentsch, T.J. 2000. ClC-5 $\mathrm{Cl}^{-}$-channel disruption impairs endocytosis in a mouse model for Dent's disease. Nature. 408:369-373.

74. Günther, W., Piwon, N., and Jentsch, T.J. 2003. The ClC-5 chloride channel knock-out mouse: an animal model for Dent's disease. Pflügers Arch. 445:456-462.

75. Gekle, M., Mildenberger, S., Freudinger, R., and Silbernagl, S. 1995. Endosomal alkalinization reduces Jmax and $\mathrm{Km}$ of albumin receptor-mediated endocytosis in OK cells. Am. J. Physiol. 268:F899-F906.

76. Maranda, B., et al. 2001. Intra-endosomal pH-sensitive recruitment of the Arf-nucleotide exchange factor ARNO and Arf6 from cytoplasm to proximal tubule endosomes. J. Biol. Chem. 276:18540-18550.

77. Christensen, E.I., et al. 2003. Loss of chloride channel ClC-5 impairs endocytosis by defective trafficking of megalin and cubilin in kidney proximal tubules. Proc. Natl. Acad. Sci. U. S. A 100:8472-8477.

78. Leheste, J.R., et al. 1999. Megalin knockout mice as an animal model of low molecular weight proteinuria. Am. J. Pathol. 155:1361-1370.

79. Cutillas, P.R., et al. 2004. The urinary proteome in Fanconi syndrome implies specificity in the reabsorption of proteins by renal proximal tubule cells. Am. J. Physiol. Renal Physiol. 287:F353-F364.

80. Nykjaer, A., et al. 1999. An endocytic pathway essential for renal uptake and activation of the steroid 25-(OH) vitamin D3. Cell. 96:507-515.

81. Christensen, E.I., et al. 1999. Evidence for an essential role of megalin in transepithelial transport of retinol. J. Am. Soc. Nephrol. 10:685-695.

82. Hilpert, J., et al. 1999. Megalin antagonizes activation of the parathyroid hormone receptor. J. Biol. Chem. 274:5620-5625

83. Norden, A.G., et al. 2001. Glomerular protein sieving and implications for renal failure in Fanconi syndrome. Kidney Int. 60:1885-1892.

84. Scheinman, S.J. 1998. X-linked hypercalciuric nephrolithiasis: clinical syndromes and chloride channel mutations. Kidney Int. 53:3-17.

85. Wang, S.S., et al. 2000. Mice lacking renal chloride channel, CLC-5, are a model for Dent's disease, a nephrolithiasis disorder associated with defective receptor-mediated endocytosis. Hum. Mol. Genet. 9:2937-2945.

86. Silva, I.V., et al. 2003. The ClC-5 knockout mouse model of Dent's disease has renal hypercalciuria and increased bone turnover. J. Bone Miner. Res. 18:615-623.

87. Murer, H., et al. 1999. Posttranscriptional regulation of the proximal tubule NaPi-II transporter in response to PTH and dietary Pi. Am. J. Physiol. 277:F676-F684.

88. Lloyd, S.E., et al. 1997. Characterisation of renal chloride channel, CLCN5, mutations in hypercalciuric nephrolithiasis (kidney stones) disorders. Hum. Mol. Genet. 6:1233-1239.

89. Morimoto, T., et al. 1998. Mutations in CLCN5 chloride channel in Japanese patients with low molecular weight proteinuria. J. Am. Soc. Nephrol. 9:811-818.

90. Igarashi, T., et al. 1998. Functional characterization of renal chloride channel, CLCN5, mutations associated with Dent's Japan disease. Kidney Int. 54:1850-1856.

91. Hoopes, R.R., Jr., et al. 2004. Evidence for genetic heterogeneity in Dent's disease. Kidney Int. 65:1615-1620.

92. Hoopes, R.R., Jr., et al. 2005. Dent Disease with mutations in OCRL1. Am. J. Hum. Genet. 76:260-267.

93. Stobrawa, S.M., et al. 2001. Disruption of ClC-3, a chloride channel expressed on synaptic vesicles, leads to a loss of the hippocampus. Neuron. 29:185-196.

94. Yoshikawa, M., et al. 2002. CLC-3 deficiency leads to phenotypes similar to human neuronal ceroid lipofuscinosis. Genes Cells. 7:597-605.

95. Hara-Chikuma, M., et al. 2005. ClC-3 chloride channels facilitate endosomal acidification and chloride accumulation. J. Biol. Chem. 280:1241-1247.

96. Kornak, U., et al. 2001. Loss of the ClC-7 chloride channel leads to osteopetrosis in mice and man. Cell. 104:205-215.

97. Kasper, D., et al. 2005. Loss of the chloride channel ClC-7 leads to lysosomal storage disease and neurodegeneration. EMBOJ. 24:1079-1091.

98. Cleiren, E., et al. 2001. Albers-Schönberg disease (autosomal dominant osteopetrosis, type II) results from mutations in the ClCN7 chloride channel gene. Hum. Mol. Genet. 10:2861-2867.

99. Koch, M.C., et al. 1992. The skeletal muscle chloride channel in dominant and recessive human myotonia. Science. 257:797-800.

100.Pusch, M., Steinmeyer, K., Koch, M.C., and Jentsch, T.J. 1995. Mutations in dominant human myotonia congenita drastically alter the voltage dependence of the ClC-1 chloride channel. Neuron. 15:1455-1463.

101.Scheel, O., Zdebik, A.A., Lourdel, S., and Jentsch, T.J. 2005. Voltage-dependent electrogenic chloride-proton exchange by endosomal CLC proteins. Nature. In press.

102.Picollo, A., and Pusch, M. 2005. Chloride/proton antiporter activity of mammalian CLC proteins ClC-4 and ClC-5. Nature. In press. 